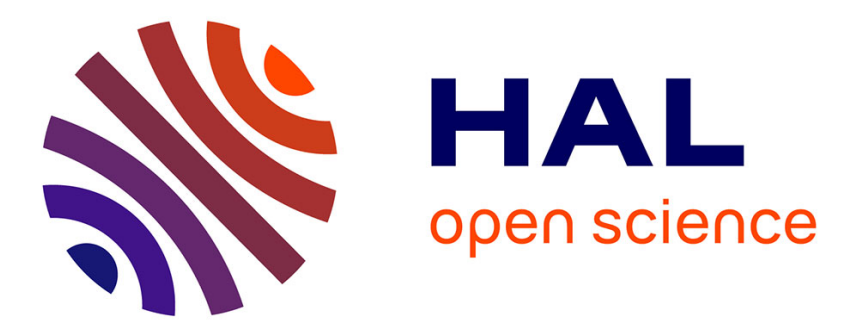

\title{
APOL1 risk genotype in Europe: Data in patients with focal segmental glomerulosclerosis and after renal transplantation
}

Aude Servais, Olivier Gribouval, François Gaillard, Corinne Antignac

\section{To cite this version:}

Aude Servais, Olivier Gribouval, François Gaillard, Corinne Antignac. APOL1 risk genotype in Europe: Data in patients with focal segmental glomerulosclerosis and after renal transplantation. Néphrologie \& Thérapeutique, 2019, 15, pp.S85 - S89. 10.1016/j.nephro.2019.02.005 . hal-03484976

\author{
HAL Id: hal-03484976 \\ https://hal.science/hal-03484976
}

Submitted on 20 Dec 2021

HAL is a multi-disciplinary open access archive for the deposit and dissemination of scientific research documents, whether they are published or not. The documents may come from teaching and research institutions in France or abroad, or from public or private research centers.
L'archive ouverte pluridisciplinaire HAL, est destinée au dépôt et à la diffusion de documents scientifiques de niveau recherche, publiés ou non, émanant des établissements d'enseignement et de recherche français ou étrangers, des laboratoires publics ou privés.

\section{(ㄷ)(1) $\$$}

Distributed under a Creative Commons Attribution - NonCommerciall 4.0 International 


\section{APOL1 risk genotype in Europe: data in patients with focal segmental glomerulosclerosis and after renal transplantation}

Aude Servais a,b,c,d*, Olivier Gribouval a,b,c, François Gaillard ${ }^{\mathrm{d}}$, Corinne Antignac a,b,c,e

${ }^{\text {a } I n s e r m ~ U 1163, ~ 24, ~ b d ~ d u ~ M o n t p a r n a s s e, ~} 75015$ Paris, France

${ }^{\mathrm{b}}$ Institut Imagine, 24, bd du Montparnasse, 75015 Paris, France

${ }^{\mathrm{c}}$ Université Paris Descartes, 24, bd du Montparnasse, 75015 Paris, France

${ }^{d}$ Nephrology and Transplantation Department, hôpital Necker-Enfants-malades, APHP, 149, rue de Sèvres, 75015 Paris, France

${ }^{\mathrm{e}}$ Genetic Department, hôpital Necker-Enfants-malades, APHP, 149, rue de Sèvres, 75015 Paris, France

*Corresponding author: Dr Aude Servais; Phone: 331 44381515; Fax: 331444954 50; E-mail: aude.servais@aphp.fr.

No disclosure of interests to declare 


\begin{abstract}
Apolipoprotein L1 (APOL1) risk variants are strongly associated with sporadic focal segmental glomerulosclerosis in populations with African ancestry. We determined the frequency of G1/G2 variants in patients with steroid-resistant nephrotic syndrome/focal segmental glomerulosclerosis with African or French West Indies origin in France and its relationships with other steroid-resistant nephrotic syndrome genes. In a cohort of 152 patients (139 families), the APOL1 risk variants were genotyped: the two risk allele (high risk) genotype was found in $43.1 \%$ of subjects compared to $18.9 \%$ in a control population $(\mathrm{p}<0.0001)$. Compared to patients in the low risk group, patients in the high risk group were more likely to originate from French West Indies than from Africa. APOL1 high risk genotype was more frequent in young adult patients, but it was also found in children and it was associated with a bad renal prognosis. APOL1 high risk genotype was usually not associated with other causative mutation in known monogenic steroid-resistant nephrotic syndrome genes and families in which multiple individuals have focal segmental glomerulosclerosis may have APOL1associated disease. After renal transplantation, recipients of deceased-donor kidney transplantation from individuals with recent African ancestry possessing two APOL1 high-risk variants have slightly shorter allograft survival. Effects of APOL1 are independent of other traditional risk factors. Recently it was shown that black living kidney donors homozygous for APOL1 high-risk alleles have significantly lower glomerular filtration rate and increased risk of end-stage renal disease after donation. However, APOL1 genotype may not summarize by itself the totality of this risk. We showed that living kidney donors of African ancestry in France with low-risk APOL1 genotype have lower post-donation eGFR increase and lower baseline kidney volume compared to Caucasian donors.
\end{abstract}

\title{
Keywords
}

APOL1, Focal segmental glomerulosclerosis, Steroid-resistant nephrotic syndrome, Kidney transplantation, Living donor

\section{Introduction}

Apolipoprotein L1 (APOL1)-associated nephropathies are a spectrum of related nondiabetic kidney diseases strongly associated with $\mathrm{G} 1$ and $\mathrm{G} 2$ coding risk variants in populations with African ancestry. It has been observed that African Americans have a fourfold increased risk for end-stage renal disease. Two studies identified a locus on chromosome 22 associated with nondiabetic end-stage renal disease, focal segmental glomerulosclerosis, human immunodeficiency virus (HIV)-associated nephropathy (which is manifested as collapsing glomerulopathy), and this was extended to hypertension-attributed end-stage renal disease [1, 2]. The major source of genetic risk for African American hypertension-attributed end-stage renal disease and focal segmental glomerulosclerosis was then localized to APOL1, encoding apolipoprotein L1 (ApoL1) [3]. Focal segmental glomerulosclerosis, HIV-associated nephropathy, hypertension-attributed end-stage renal disease, hypertension-attributed chronic renal failure, non-diabetic end-stage renal disease were associated with two APOL1 risk alleles: $\mathrm{G} 1$, comprising two missense variants (S342G and I384M), and G2, which bears a 6-base-pair in-frame deletion leading to the deletion of two amino acids (N388_Y389del) [37]. $\mathrm{G} 1$ and $\mathrm{G} 2$ are mutually exclusive, never occurring on the same chromosome. In particular, these variants were strongly associated with sporadic focal segmental glomerulosclerosis in either the homozygous or compound heterozygous state with a recessive pattern of inheritance. One risk allele was associated with only a small increase in renal disease risk. Two risk alleles versus zero risk alleles yielded an odd ratio from 10 to 17 for focal segmental glomerulosclerosis [3, 4]. 
ApoL1 is the trypanolytic factor of human serum that confers resistance to Trypanosoma brucei brucei. In vitro studies revealed that only the kidney disease-associated ApoL1 variants lyse Trypanosoma brucei rhodesiense, one of the causes of human African sleeping sickness. APOL1 gene may have undergone natural selective pressure in Western Africa [3].

\section{APOL1 risk genotype in European patients of different African ancestries, with focal}

\section{segmental glomerulosclerosis}

We analysed APOL1 risk allele genotype frequency in a large cohort of 152 patients with focal segmental glomerulosclerosis, of African ancestry living in Europe [8]. The two risk allele genotype was frequent (high risk group), found in $43 \%$ of patients in the whole cohort and in $60 \%$ of patients originating from French West Indies, significantly higher than in controls $(18.9 \%, p<0.0001)$. The frequency of the two risk allele genotype in patients originating from French West Indies in our study is similar to that observed in African American patients with focal segmental glomerulosclerosis: the APOL1 risk genotype was present in $60 \%$ to $72 \%$ of self-identified African-American patients with focal segmental glomerulosclerosis in previous studies compared to 12.5 to $13 \%$ in controls $[3,4,9$ $11]$.

To analyse the relative roles of APOL1 and of the genes known to be involved in focal segmental glomerulosclerosis/ steroid-resistant nephrotic syndrome in these patients, we screened for pathogenic mutations with a panel including 35 steroid-resistant nephrotic syndrome genes. Of note, $41.5 \%$ of patients had a familial disease in the APOL1 high risk group, whereas a mutation in steroid-resistant nephrotic syndrome genes was found in only one. Most of the mutations in monogenic steroid-resistant nephrotic syndrome genes were found in young patients in the APOL1 low risk group. Because of the high frequency of G1 and G2 and the large increased risk of focal segmental glomerulosclerosis associated with these variants, families in which multiple individuals have the disease may have APOL1-associated disease rather than one of the rarer Mendelian forms of disease. Accordingly, it has been shown that relatives of African American with non-diabetic endstage renal disease are enriched for APOL1 risk variants [12].

Patients in the high risk group were more likely to originate from French West Indies than from Africa. Among patients originating from Africa, most patients originated from West Africa. This is concordant with the prevailing hypothesis that $\mathrm{G} 1$ and to a lesser degree $\mathrm{G} 2$ renal risk alleles rose to high frequencies in West Africa because of positive selection by Trypanosoma brucei rhodesiense, the causal agent of acute human African trypanosomiasis [13]. The variants are found outside Africa at high frequencies in persons of African ancestry. The transatlantic slave trade resulted in the forced diaspora of millions of Africans from the Atlantic coastal regions of Africa to the Caribbean and the Americas [13]. The high allele frequencies of APOL1 G1 and G2 variants in African Americans and in Caribbean reflect the APOL1 G1 and G2 frequencies along the Atlantic coast of Africa. The higher frequency observed in patients originating from the French West Indies compared to patients originating from Africa might be due the fact that a high proportion of them originated from West Central Africa, in particular Nigeria, where a very high prevalence of the high risk genotype is observed in the general population compared to other countries of West Africa [14].

We showed that APOL1-associated focal segmental glomerulosclerosis in our cohort presented at a broad age range between 0 and 64 years, but in the majority of patients the disease was diagnosed between 6 and 40 years and 54\% were adults. Age at onset according to APOL1 high risk allele or mutation in steroid-resistant nephrotic syndrome genes is presented on Figure 1. In very young children with disease onset before 1 year of age, a mutation in monogenic steroid-resistant nephrotic syndrome genes was more likely to be identified. Together these data support the idea 
that focal segmental glomerulosclerosis among APOL1 high risk individuals is a disease presenting during childhood and early adulthood.

Most patients had normal blood pressure in both groups. It demonstrates that focal segmental glomerulosclerosis associated with APOL1 high risk genotype are distinct from hypertensive nephropathies associated with APOL1 high risk genotype. Numerically more patients presented with collapsing focal segmental glomerulosclerosis in the APOL1 high risk group and more patients with minimal change disease in the low risk group but it was not statistically significant.

Baseline and last follow up estimated glomerular filtration rate were significantly lower among patients with the APOL1 high risk genotype, which is consistent with the faster progression rate that has been observed in these individuals in two previous studies [4, 5]. In our study, renal survival also tended to be worse in patients with the APOL1 high risk genotype (Figure 2). Due to its prognostic value, we suggest to add APOL1 in gene panels used in steroid-resistant nephrotic syndrome.

As APOL1-associated focal segmental glomerulosclerosis has a propensity to progress rapidly to end-stage renal disease, the question of treatment is crucial. In a previous study, the frequency of glucocorticoids sensitivity was similar in subjects with two APOL1 risk alleles $(12 / 42,29 \%)$, and in subjects with zero or one APOL1 risk allele (5/15, 33\%) [4]. Furthermore, APOL1 risk genotype did not seem to affect response to other immunosuppressive treatment regimen [5]. In the NEPTUNE study, APOL1 high risk genotype was associated with a $69 \%$ reduction in the probability of complete remission at any time, independent of histologic diagnosis [4, 11]. In our study, 94 percent of patients were steroid-resistant, since most samples were addressed because of steroid-resistance for genetic testing. In the high risk group, all patients were steroid-resistant and only very few could be retrospectively considered as immune forms. In a recent study, it has been shown that APOL1 highrisk variants are not associated with steroid-sensitive nephrotic syndrome but show significant associations with steroid-resistant nephrotic syndrome [15]. This is concordant with the clinical and experimental data showing the role of the intracellular expression of APOL1 in the podocytes[16].

\section{APOL1 and kidney transplantation}

\subsection{APOL1 in deceased-donor kidney transplantation}

Contrary to the association seen in native kidney disease, there is no difference in allograft survival at 5 years post-transplant for recipients with high-risk APOL1 genotypes. APOL1 recipient genotypes do not increase risk of allograft loss after kidney transplantation [17].

The effect of transplanting kidneys from deceased African American donors with two APOL1 nephropathy risk variants was also studied. First, APOL1 risk variants were genotyped in 106 African American deceased organ donors and graft survival assessed in 136 resultant kidney transplants. Twenty-two of 136 transplanted kidneys (16\%) were from donors with two APOL1 high-risk variants. A multivariate model revealed that graft survival was significantly shorter in donor kidneys with two APOL1 risk variants, but not for overall African ancestry excluding APOL1 [18]. A second study included an additional 548 patients from 55 centers [19]. The latter report generally confirmed the previous findings: presence of two APOL1 high-risk variants in donors appeared to translate into heightened risk for earlier allograft failure after deceased-donor kidney transplantation. A third study from the same team replicated and extended the observation in deceased-donor kidney transplantation by assessing the outcomes of 478 additional deceased-donor kidney transplantations from African American donors and performing a combined analysis in 1153 deceased-donor kidney 
transplantations [20]. Results strongly supported the initial observations that recipients of deceaseddonor kidney transplantation from individuals with recent African ancestry possessing two APOL1 high-risk variants had shorter allograft survival (effects of two renal risk variants were of stronger significance than possession of a single risk variant). Effects of APOL1 were independent of other traditional risk factors known to adversely impact renal allograft survival. Novel findings included that donor age did not significantly impact allograft survival based on the number of APOL1 high-risk variants and recipients of kidneys from these donors had higher serum creatinine concentrations at latest follow-up.

Viral infections, including active cytomegalovirus infection, are possible "second hits" that may lead to glomerular injury and allograft failure in APOL1 high-risk recipients [21]. Furthermore, de novo post-transplant collapsing focal segmental glomerulosclerosis is associated with potential predisposing factors such as acute rejection, viral infection and acute vaso-occlusion[22]. In these de novo post transplant focal segmental glomerulosclerosis, donor APOL1 high-risk genotype independently predicts poor outcome.

\subsection{APOL1 in living-donor kidney transplantation}

Living kidney donation provides best results for patients and graft survival compared to deceased kidney donors [23]. Overall, living kidney donation is safe and donors have an absolute risk of endstage renal disease significantly lower than general population [24]. However, it is now recognized that living kidney donation increases the relative risk of end stage renal disease compared to healthy non-donors [24, 25]. The magnitude of end-stage renal disease risk increase varies according to sex, age and race $[24,26]$. It has been shown that black donors have an increased risk of hypertension and end-stage renal disease compared with matched black non donors [24, 27]. The risk of end-stage renal disease is also higher among donors biologically related to the recipients [24, 25].

It is possible that the increased risk of renal failure after kidney donation could be explained by APOL1 high-risk alleles that are shared between the donor and their related recipient. Young blacks with good baseline health-suitable potential donors who did not donate-carrying the APOL1 high-risk alleles are at higher risk of developing chronic kidney disease in the future [28].

Two case reports mentioned focal segmental glomerulosclerosis and end-stage renal disease occurring within 7 years in donors harboring the APOL1 G1 or G2 variants [29, 30]. Recently it was shown that black living kidney donors homozygous for APOL1 high-risk alleles had significantly lower glomerular filtration rate and increased risk of end-stage renal disease after donation [31]. In that study, patients were divided into APOL1 high-risk ( $n=19)$ or low-risk $(n=117)$ genotypes. Donors in the APOL1 high-risk group had a $10 \mathrm{ml} / \mathrm{min}$ predonation lower estimated glomerular filtration rate. At a median of 12 years after donation, donors with the APOL1 high-risk genotype had a lower estimated glomerular filtration rate $\left(57 \pm 18\right.$ versus $67 \pm 15 \mathrm{ml} / \mathrm{min}$ per $\left.1.73 \mathrm{~m}^{2} ; \mathrm{P}=0.02\right)$ and a faster decline in estimated glomerular filtration rate after adjusting for predonation estimated glomerular filtration rate (1.19 versus $0.4 \mathrm{ml} / \mathrm{min} /$ year). Two donors developed end-stage renal disease; both carried the APOL1 high-risk genotype. However, decline in estimated glomerular filtration rate between donors and matched non donors grouped by APOL1 genotype was similar.

The systematic screening of $A P O L 1$ gene variants is still under debate, but the recently published guidelines from Kidney Disease: Improving Global Outcomes (KDIGO) suggest to propose APOL1 genotyping in black donors at risk [32]. 


\subsection{Post-donation kidney function of low-risk APOL1 genotype living kidney donors of African} ancestry

APOL1 high-risk genotype may not summarize the totality of end-stage renal disease risk increase in donors. In France, we analyzed a cohort of 38 donors of African ancestry and determined their APOL1 status [33]. We showed that $7(18 \%)$ had a APOL1 high risk genotype. At donation and 1 year after donation, these $A P O L 1$ high risk genotype donors tended to have a $9 \mathrm{ml} / \mathrm{min} / 1.73 \mathrm{~m}^{2}$ and 5 $\mathrm{ml} / \mathrm{min} / 1.73 \mathrm{~m}^{2}$ lower estimated glomerular filtration rate than low risk patients, respectively, but it did not reach significance, probably because of the limited number of participants and of the short follow up. We then focused on the low risk APOL1 group of donors. We compared compensatory response of the remaining kidney 1 year after donation between living kidney donors of Caucasian and African origin. We matched 62 Caucasian living kidney donors with 31donors of African descent with low-risk APOL1 genotype on age, body mass index, measured glomerular filtration rate and sex. African and Caucasian donors had similar baseline measured glomerular filtration rate, similar baseline estimated glomerular filtration rate, and similar 1-year postdonation estimated glomerular filtration rate. However, African donors had a lower absolute estimated glomerular filtration rate increase after donation compared to Caucasian donors. Relative estimated glomerular filtration rate increase after donation tended to be lower for donors of African ancestry compared to Caucasian donors. It has been previously reported that absolute estimated glomerular filtration rate increase after donation is negatively correlated with the baseline ratio of measured glomerular filtration rate divided by the volume of the remaining kidney (measured glomerular filtration rate/volume) [34]. As absolute estimated glomerular filtration rate increase was different between groups, we compared renal volume and measured glomerular filtration rate/volume ratio. At baseline, African donors had lower remaining-kidney volume compared to Caucasian donors and remaining kidney "measured glomerular filtration rate/volume" ratio was higher in donors of African descent compared to Caucasian donors. For donors of African ancestry, lower kidney volume could reflect reduced nephron number [35]. Since baseline measured glomerular filtration rate is similar in both groups, reduced nephron number in African donors could reflect higher baseline single nephron glomerular filtration rate. The "already high" single nephron glomerular filtration rate in donors of African ancestry could limit postdonation glomerular filtration rate increase. In agreement, donors of African descent had lower postdonation estimated glomerular filtration rate increase. Nephron-number difference between groups could be linked to a lower birth-weight of newborns of African ancestry as observed in African American [36].

\section{Conclusion}

Our results suggest that even low-risk APOL1 donors have lower compensatory response of the remaining kidney compared to Caucasian donors. Therefore, APOL1 genotype may not be sufficient to explain the discrepancy between donors of African descent and Caucasian donors. Better description of living kidney donation outcomes of donors with low-risk APOL1 genotype is needed.

\section{Funding}

The research leading to these results has received funding from the Investments for the Future Program grant ANR-10-IAHY-01 (to C.A.) and from the European Union's Seventh Framework Programme (FP7/2007-2013) grant 305608 (EURenOmics). 


\section{References}

1. Kao, W.H., M.J. Klag, L.A. Meoni, D. Reich, Y. Berthier-Schaad, M. Li, et al., MYH9 is associated with nondiabetic end-stage renal disease in African Americans. Nat Genet, 2008. 40(10): p. 1185-92.

2. Kopp, J.B., M.W. Smith, G.W. Nelson, R.C. Johnson, B.I. Freedman, D.W. Bowden, et al., MYH9 is a major-effect risk gene for focal segmental glomerulosclerosis. Nat Genet, 2008. 40(10): p. 1175-84.

3. Genovese, G., D.J. Friedman, M.D. Ross, L. Lecordier, P. Uzureau, B.I. Freedman, et al., Association of trypanolytic ApoL1 variants with kidney disease in African Americans. Science, 2010. 329(5993): p. 841-5.

4. Kopp, J.B., G.W. Nelson, K. Sampath, R.C. Johnson, G. Genovese, P. An, et al., APOL1 genetic variants in focal segmental glomerulosclerosis and HIV-associated nephropathy. J Am Soc Nephrol, 2011. 22(11): p. 2129-37.

5. Kopp, J.B., C.A. Winkler, X. Zhao, M.K. Radeva, J.J. Gassman, V.D. D'Agati, et al., Clinical features and histology of apolipoprotein L1-associated nephropathy in the FSGS clinical trial. J Am Soc Nephrol, 2015. 26(6): p. 1443-8.

6. Tzur, S., S. Rosset, R. Shemer, G. Yudkovsky, S. Selig, A. Tarekegn, et al., Missense mutations in the APOL1 gene are highly associated with end stage kidney disease risk previously attributed to the MYH9 gene. Hum Genet, 2010. 128(3): p. 345-50.

7. Lipkowitz, M.S., B.I. Freedman, C.D. Langefeld, M.E. Comeau, D.W. Bowden, W.H. Kao, et al., Apolipoprotein L1 gene variants associate with hypertension-attributed nephropathy and the rate of kidney function decline in African Americans. Kidney Int, 2013. 83(1): p. 114-20.

8. Gribouval, O., O. Boyer, B. Knebelmann, A. Karras, J. Dantal, C. Fourrage, et al., APOL1 risk genotype in European steroid-resistant nephrotic syndrome and/or focal segmental glomerulosclerosis patients of different African ancestries. Nephrol Dial Transplant, 2018. doi: 10.1093/ndt/gfy176.

9. Genovese, G., D.J. Friedman and M.R. Pollak, APOL1 variants and kidney disease in people of recent African ancestry. Nat Rev Nephrol, 2013. 9(4): p. 240-4.

10. Friedman, D.J., J. Kozlitina, G. Genovese, P. Jog and M.R. Pollak, Population-based risk assessment of APOL1 on renal disease. J Am Soc Nephrol, 2011. 22(11): p. 2098-105.

11. Sampson, M.G., C.C. Robertson, S. Martini, L.H. Mariani, K.V. Lemley, C.E. Gillies, et al., Integrative genomics identifies novel associations with APOL1 risk genotypes in black NEPTUNE subjects. J Am Soc Nephrol, 2016. 27(3): p. 814-23.

12. Freedman, B.I., C.D. Langefeld, J. Turner, M. Nunez, K.P. High, M. Spainhour, et al., Association of APOL1 variants with mild kidney disease in the first-degree relatives of African American patients with non-diabetic end-stage renal disease. Kidney Int, 2012. 82(7): p. 805-11.

13. Limou, S., G.W. Nelson, J.B. Kopp and C.A. Winkler, APOL1 kidney risk alleles: population genetics and disease associations. Adv Chronic Kidney Dis, 2014. 21(5): p. 426-33.

14. Rotimi Ch, T.A.F., Baker J, Shriner D, The African diaspora: history, adaptation and health. Curr Opin Genet Dev, 2016. 41: p. 77-84. 
15. Adeyemo, A., C. Esezobor, A. Solarin, A. Abeyagunawardena, J.A. Kari, S. El Desoky, et al., $H L A-D Q A 1$ and $A P O L 1$ as risk loci for childhood-onset steroid-sensitive and steroid-resistant nephrotic syndrome. Am J Kidney Dis, 2018. 71(3): p. 399-406.

16. Bruggeman, L.A., J.F. O'Toole and J.R. Sedor, Identifying the intracellular function of ApoL1. J Am Soc Nephrol, 2017. 28(4): p. 1008-1011.

17. Lee, B.T., V. Kumar, T.A. Williams, R. Abdi, A. Bernhardy, C. Dyer, et al., The APOL1 genotype of African American kidney transplant recipients does not impact 5-year allograft survival. Am J Transplant, 2012. 12(7): p. 1924-8.

18. Reeves-Daniel, A.M., J.A. DePalma, A.J. Bleyer, M.V. Rocco, M. Murea, P.L. Adams, et al., The APOL1 gene and allograft survival after kidney transplantation. Am J Transplant, 2011. 11(5): p. 102530.

19. Freedman, B.I., B.A. Julian, S.O. Pastan, A.K. Israni, D. Schladt, M.D. Gautreaux, et al., Apolipoprotein L1 gene variants in deceased organ donors are associated with renal allograft failure. Am J Transplant, 2015. 15(6): p. 1615-22.

20. Freedman, B.I., S.O. Pastan, A.K. Israni, D. Schladt, B.A. Julian, M.D. Gautreaux, et al., APOL1 genotype and kidney transplantation outcomes from deceased African American donors. Transplantation, 2016. 100(1): p. 194-202.

21. Chang, J.H., S.A. Husain, D. Santoriello, M.B. Stokes, C.D. Miles, K.W. Foster, et al., Donor's $A P O L 1$ risk genotype and "second hits" associated with de novo collapsing glomerulopathy in deceased donor kidney transplant recipients: a report of 5 cases. Am J Kidney Dis, 2019. 73(1): p. 134-139.

22. Santoriello, D., S.A. Husain, S.A. De Serres, A.S. Bomback, R.J. Crew, E.R. Vasilescu, et al., Donor APOL1 high-risk genotypes are associated with increased risk and inferior prognosis of de novo collapsing glomerulopathy in renal allografts. Kidney Int, 2018. 94(6): p. 1189-1198.

23. Terasaki, P.I., J.M. Cecka, D.W. Gjertson and S. Takemoto, High survival rates of kidney transplants from spousal and living unrelated donors. N Engl J Med, 1995. 333(6): p. 333-6.

24. Muzaale, A.D., A.B. Massie, M.C. Wang, R.A. Montgomery, M.A. McBride, J.L. Wainright, et al., Risk of end-stage renal disease following live kidney donation. JAMA, 2014. 311(6): p. 579-86.

25. Mjoen, G., S. Hallan, A. Hartmann, A. Foss, K. Midtvedt, O. Oyen, et al., Long-term risks for kidney donors. Kidney Int, 2014. 86(1): p. 162-7.

26. Grams, M.E., A.X. Garg and K.L. Lentine, Kidney-failure risk projection for the living kidneydonor candidate. N Engl J Med, 2016. 374(21): p. 2094-5.

27. Doshi, M.D., M.O. Goggins, L. Li and A.X. Garg, Medical outcomes in African American live kidney donors: a matched cohort study. Am J Transplant, 2013. 13(1): p. 111-8.

28. Locke J.E., D. Sawinski, R.D. Reed, B. Shelton, P.A. MacLennan, V. Kumar, et al., Apolipoprotein L1 and chronic kidney disease risk in young potential living kidney donors. Ann Surg, 2018;267(6):1161-1168.

29. Zwang, N.A., A. Shetty, N. Sustento-Reodica, E.J. Gordon, J. Leventhal, L. Gallon, et al., Apol1associated end-stage renal disease in a living kidney transplant donor. Am J Transplant, 2016;16(12):3568-3572. 
30. Kofman, T., V. Audard, C. Narjoz, O. Gribouval, M. Matignon, C. Leibler, et al., APOL1 polymorphisms and development of CKD in an identical twin donor and recipient pair. Am J Kidney Dis, 2014. 63(5): p. 816-9.

31. Doshi, M.D., M. Ortigosa-Goggins, A.X. Garg, L. Li, E.D. Poggio, C.A. Winkler, et al., APOL1 genotype and renal function of black living donors. J Am Soc Nephrol, 2018;29(4):1309-1316.

32. Lentine, K.L., B.L. Kasiske, A.S. Levey, P.L. Adams, J. Alberu, M.A. Bakr, et al., KDIGO clinical practice guideline on the evaluation and care of living kidney donors. Transplantation, 2017. 101(8S Suppl 1): p. S1-S109.

33. Gaillard, F., O. Gribouval, M. Courbebaisse, C. Fournier, C. Antignac, C. Legendre, et al., Comparison of postdonation kidney function between caucasian donors and low-risk APOL1 genotype living kidney donors of African ancestry. Transplantation, 2018. 102(11): p. e462-e463.

34. Courbebaisse, M., F. Gaillard, A.M. Tissier, C. Fournier, A. Le Nestour, J.M. Correas, et al., Association of $\mathrm{mGFR}$ of the remaining kidney divided by its volume before donation with functional gain in mGFR among living kidney donors. Clin J Am Soc Nephrol, 2016. 11(8): p. 1369-76.

35. Nyengaard, J.R. and T.F. Bendtsen, Glomerular number and size in relation to age, kidney weight, and body surface in normal man. Anat Rec, 1992. 232(2): p. 194-201.

36. Anachebe, N.F. and M.Y. Sutton, Racial disparities in reproductive health outcomes. Am J Obstet Gynecol, 2003. 188(4): p. S37-42. 


\section{Figure legends}

Figure 1. Percentage of patients with mutation of steroid-resistant nephrotic syndrome genes or $A P O L 1$ variant detected in relation to age of onset of proteinuria. Histograms indicate fraction (in percentage) of patients with mutation detected in $n$ patients per $N$ patients examined per age group (on top of histograms). Reproduced from [8].

Figure 2. Renal survival in the high risk (HR) and low risk (LR) groups by Kaplan Meyer analysis $(p=0.06)$. Reproduced from [8]. 


\section{Age at onset of proteinuria}

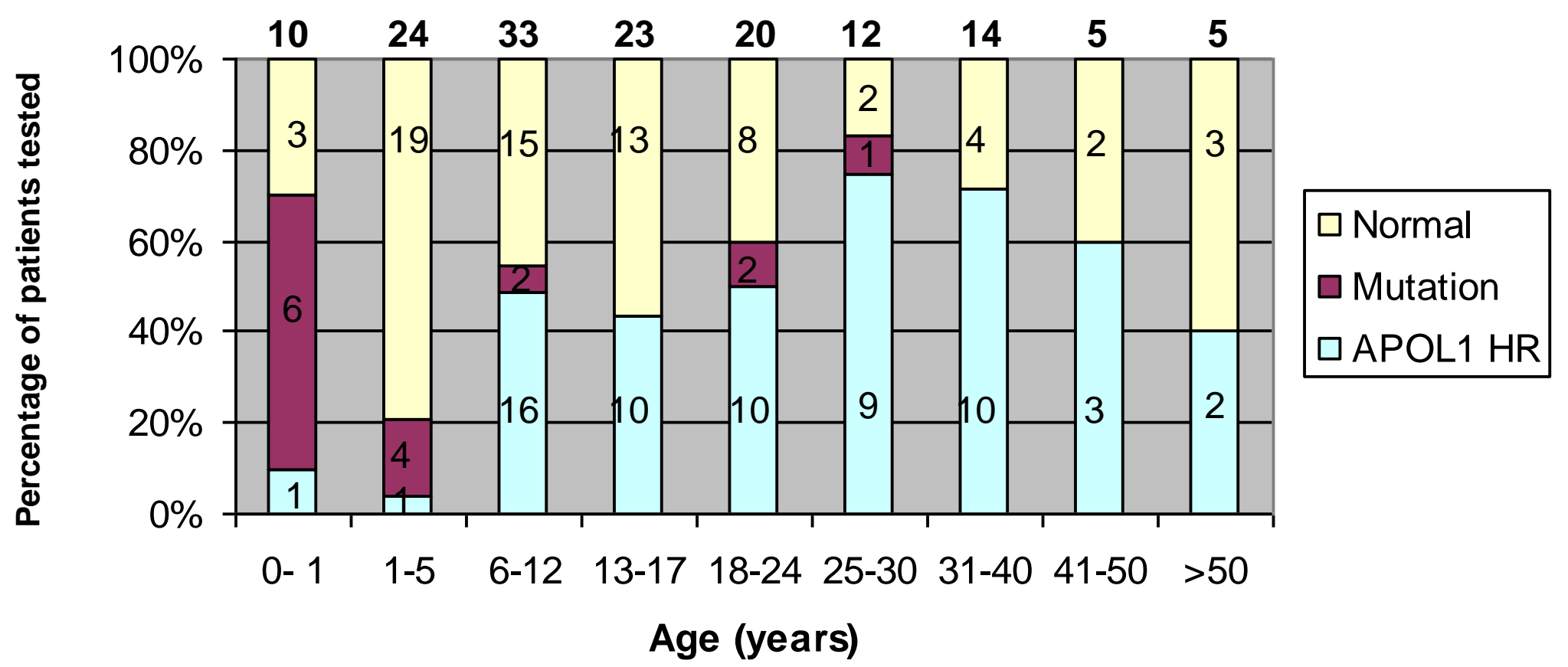




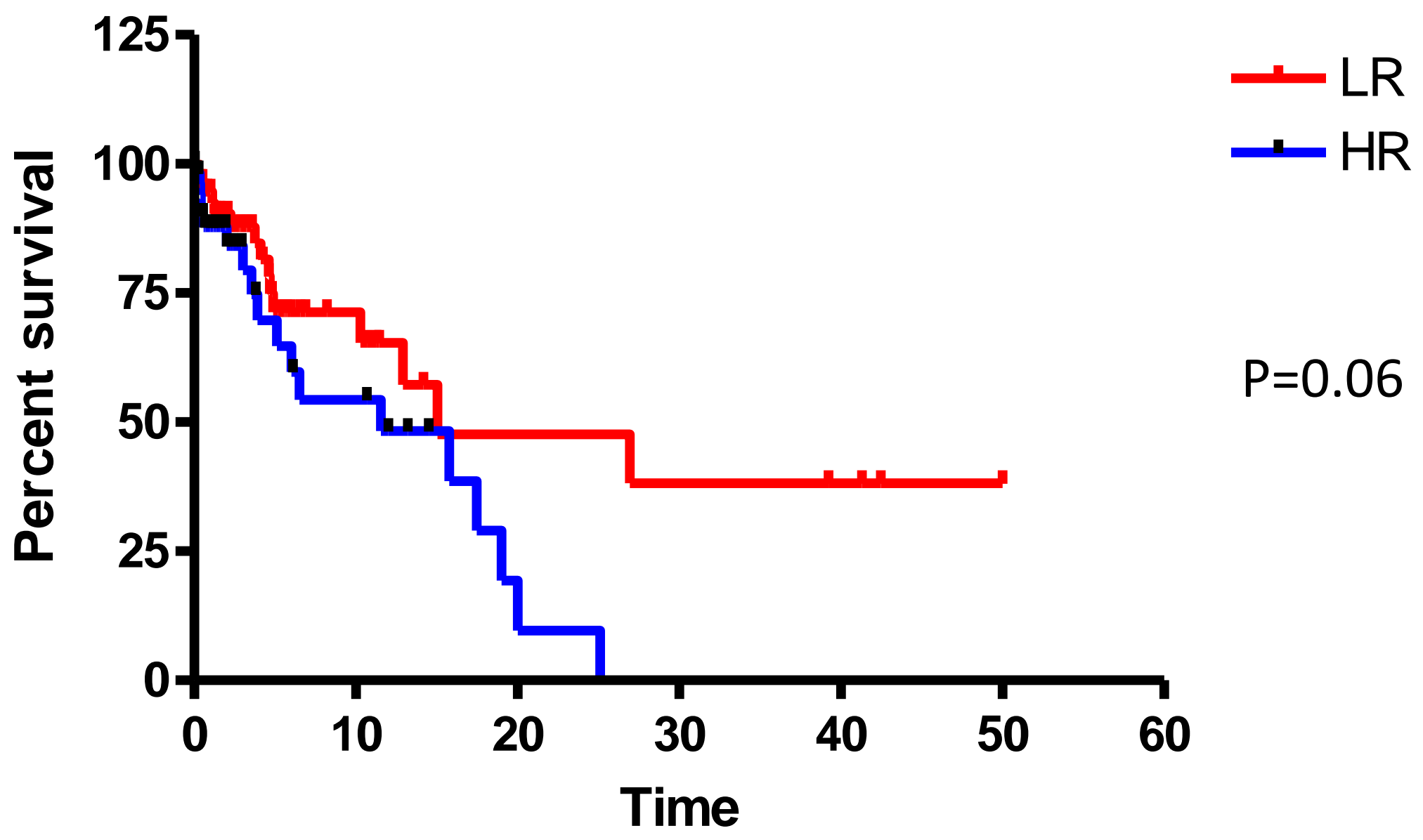

